\title{
Cholecystoduodenal fistula diagnosed with contrast-enhanced endoscopic ultrasound
}

A 58-year-old man with a history of Crohn's disease (A2L2B1 p), bile stones, migraine, and chronic depression presented with an 11-kg weight loss and asthenia during the preceding 6 months. He was receiving treatment with infliximab, azathioprine, mirtazapine, and lorazepam. Laboratory tests showed a slightly elevated C-reactive protein (CRP) of $35 \mathrm{mg} / \mathrm{dL}$. He underwent a computed tomography (CT) scan that demonstrated gallbladderwall calcification, with no cleavage plane between the second portion of the duodenum and the gallbladder ( $\bullet$ Fig. 1 ).

Upper gastrointestinal endoscopy showed that the duodenal bulb had a bulky appearance with ulceration of the anterior duodenal wall ( $\bullet$ Fig.2). Luminal contrast-enhanced endoscopic ultrasound (EUS) with instillation of a 50/50 polyethylene glycol and distilled water solution was used to create a hyperechogenic lumen. Shortly after this, a hyperechoic fistula tract was observed connecting the duodenal wall to the gallbladder wall ( Video 1).

The patient underwent cholecystectomy with fistula section and closure of the duodenal fistula orifice. Pathological examination revealed chronic inflammation of the duodenal mucosa that was adherent to the gallbladder wall, including an acute necrohemorrhagic inflammatory process with perforation and fibrosis related to intramural lithiasis. The patient's recovery after surgery was unremarkable and 2 months after the procedure he had gained $4 \mathrm{~kg}$.

Spontaneous enterobiliary fistula is a complication that is typically associated with gallstones (90\%) [1]. It has also been reported with abdominal trauma, Crohn's disease, peptic ulcer disease, and malignancies of the biliary tract, bowel, and pancreas $[2,3]$. The symptoms associated

\section{Video 1}

Contrast-enhanced endoscopic ultrasound (EUS) demonstrating a hyperechoic fistula tract between the duodenum and the gallbladder wall after instillation of luminal contrast.

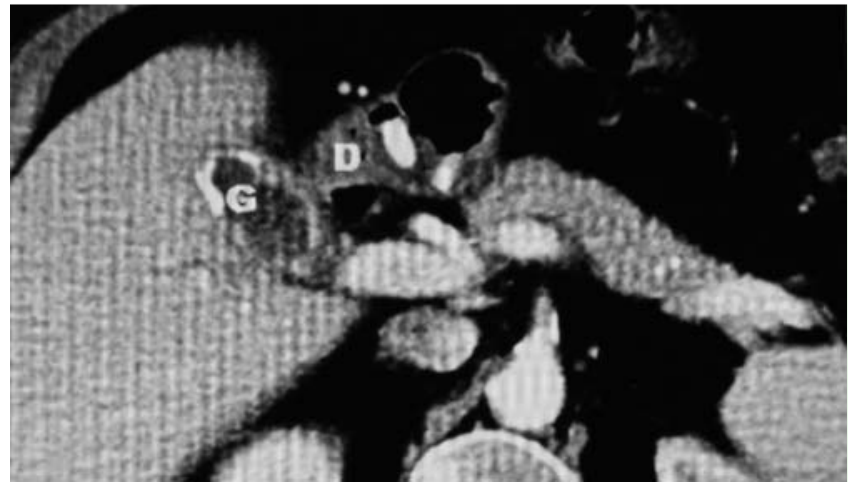

Fig. 1 Computed tomography (CT) image obtained after the administration of intravenous contrast showing calcification of the gallbladder wall, the absence of a cleavage plane between the second portion of the duodenum (D) and the gallbladder (G).

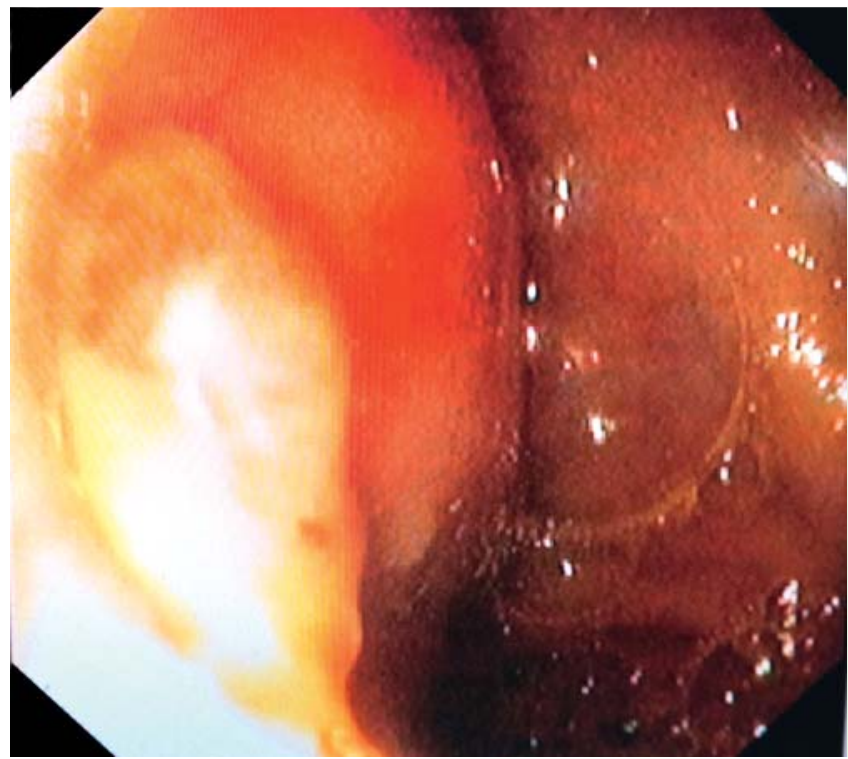

Fig. 2 View during upper gastrointestinal endoscopy showing a bulky appearance of the duodenal bulb, with ulceration of the anterior duodenal wall.

with enterobiliary fistulas are nonspecific, with presenting features often including abdominal pain, nausea, weight loss, and obstruction of the small bowel or colon by the gallstone. Recurrent episodes of untreated cholecystitis caused by stone obstruction of the cystic duct can produce adhesions between the gallbladder and bowel, as in this case [4]. Most reported cases are identified intraoperatively during laparoscopic surgery. In this case, preoperative diagnosis was possible using luminal contrast-enhanced EUS.

Endoscopy_UCTN_Code_CCL_1AF_2AF

Competing interests: None

\section{Velosa ${ }^{1,2}$, S. Lopes ${ }^{1,3}$, R. Castro ${ }^{4}$, C. Macedo ${ }^{1,3}$}

1 Serviço de Gastrenterologia, Hospital S. João, Porto, Portugal

2 Serviço de Gastrenterologia, Hospital Dr. Nélio Mendonça, Funchal, Madeira, Portugal

${ }^{3}$ Serviço de Gastrenterologia, Faculdade de Medicina da Universidade do Porto, Porto, Portugal

${ }^{4}$ Serviço de Imagiologia, Hospital S. João, Porto, Portugal 


\section{References}

1 Noskin EA, Strauus AA, Strauss FF. Spontaneous internal biliary fistula: a review of literature and report of two cases. Ann Surg 1949; 130: 270

2 LeBlanc KA, Barr LH, Rush BM. Spontaneous biliary enteric fistulas. South Med J 1983; 76: 1240 - 1253

3 Yamamoto T, Abe K, Anjiki $\mathrm{H}$ et al. Choledochoduodenal fistula associated with recurrent peptic ulcer. J Med Cases 2012; 3: 243-246

4 Hession PR, Rawlinson J, Hall JR et al. The clinical and radiological features of cholecystocolic fistulae. Br J Radiol 1996; 69: 804-809

\section{Bibliography}

DOI http://dx.doi.org/

10.1055/s-0032-1326112

Endoscopy 2013; 45: E18-E19

(C) Georg Thieme Verlag KC

Stuttgart · New York

ISSN 0013-726X
Corresponding author

M. Velosa, MD

Caminho dos saltos n. 32

Vilas jardins d'agua, moradia $D$

9050-219, Funchal

Madeira Island

Portugal

Fax: +351-291-572538

mo.velosa@gmail.com 